DOI: 10.20472/IAC.2017.034.026

\author{
KARA KAVANAGH \\ James Madison University, United States
}

HOLLY MCCARTNEY

James Madison University, United States

\title{
INTEGRATING COMMUNITY, CREATIVITY, AND LITERACY TO SUPPORT REFUGEES TRANSITIONING TO OUR SCHOOLS AND COMMUNITY
}

\begin{abstract}
:
In summer of 2016, members of the Harrisonburg,VA (USA) refugee community, Harrisonburg City Schools, James Madison University's Department of Early, Elementary, and Reading Education, and Church World Service Refugee Resettlement Agency, implemented a three week summer program for refugee children and parents that integrated literacy, creativity, and community-based field trips. College pre-service teachers earned 6 graduate credits for organizing, implementing, and facilitating integrated lessons, morning meetings, rituals, and routines to help ease the transition of newly arrived children ages 4-9 into our community and schools. This presentation will provide an overview of how this program started and illuminate the challenges and opportunities of sustaining a partnership between universities, local schools, community agencies, and leaders in the refugee community who wish to support and advocate for refugees in their community. Findings from our empirical investigation into the pilot CARE (Creativity and Reading Education) program will be discussed. Initial findings from the second implementation of this program (Summer 2017) will also be shared.
\end{abstract}

\section{Keywords:}

refugee education, integrated teaching, parental engagement, community-based teaching, literacy, creativity 